\title{
A generalized nonlinear mixed-effects height-diameter model for Eucalyptus globulus L. in northwestern Spain
}

\author{
Felipe Crecente-Campo ${ }^{\mathrm{a}, *}$, Margarida Tomé ${ }^{\mathrm{b}}$, Paula Soares ${ }^{\mathrm{b}}$, Ulises Diéguez-Aranda ${ }^{\mathrm{a}}$ \\ a Departamento de Ingeniería Agroforestal, Universidad de Santiago de Compostela, Escuela Politécnica Superior, R/Benigno Ledo, Campus universitario, 27002, Lugo, Spain \\ ${ }^{\mathrm{b}}$ Centro de Estudos Florestais, Instituto Superior de Agronomia, Universidade Técnica de Lisboa, Tapada da Ajuda, 1349-017, Lisbon, Portugal
}

A R T I C L E I N F O

\section{Article history:}

Received 30 July 2009

Received in revised form 24 November 2009 Accepted 26 November 2009

\section{Keywords:}

Growth model

Random effects

Calibration

Unequal selection probabilities

Weighted regression

Tasmanian blue gum

\begin{abstract}
A B S T R A C T
A generalized height-diameter model was developed for Eucalyptus globulus Labill. stands in Galicia (northwestern Spain). The study involved a variety of pure stands ranging from even-aged to unevenaged. Data were obtained from permanent circular sample plots in which trees were sampled within different radii according to their diameter at breast height. A combination of weighted regression, to take into account the unequal selection probabilities of such an inventory design, and mixed model techniques, to accommodate local random fluctuations in the height-diameter relationship, were applied to estimate fixed and random parameters for several models reported in the relevant literature. The models that provided the best results included dominant height and dominant diameter as fixed effects. These models explained more than $83 \%$ of the observed variability, with mean errors of less than $2.5 \mathrm{~m}$. Random parameters for particular plots were estimated with different tree selection options. Height-diameter relationships tailored to individual plots can be obtained by calibration of the height measurements of the three smallest trees in a plot. An independent dataset was used to test the performance of the model with data not used in the fitting process, and to demonstrate the advantages of calibrating the mixed-effects model.
\end{abstract}

(c) 2009 Elsevier B.V. All rights reserved.

\section{Introduction}

Tasmanian blue gum (Eucalyptus globulus Labill.) is one of the most important tree species in Galicia (northwestern Spain). More than 3.5 million cubic meters of this eucalypt were harvested in the region in 2008 (FEARMAGA, 2009), making it the major species in terms of volume harvested. However, stands of Tasmanian blue gum lack proper management, mainly due to the lack of management tools for the species.

Measuring total height $(h)$ is not as easy as measuring diameter at breast height $(d)$. Total height is usually measured indirectly with height measuring instruments based on angle and distance measures. As a result of the difficulty in measuring tree height and the cost associated with field inventories, and as $h$ and $d$ are correlated, it is common practice to fit heightdiameter $(h-d)$ models to predict $h$ from measured $d$. Such models are thus essential for estimating individual tree volume and sometimes site index, and for describing stand growth dynamics and succession over time (Curtis, 1967) when height is not measured. Parresol (1992) described $h-d$ models as

\footnotetext{
* Corresponding author. Tel.: +34 982 285900; fax: +34 982285926

E-mail address: felipe.crecente@usc.es (F. Crecente-Campo).
}

important components in yield estimation, stand description and damage appraisal. Moreover, they are also important in characterizing canopy height diversity and wildlife habitat relationships (Spies and Cohen, 1992; Morrison et al., 1992). Dominant height, competition indices and height/diameter ratios can also be easily calculated by use of this relation, without investing large amounts of money in height measurement (Calama and Montero, 2004), at least if these variables are not included in the model formulation. Finally, Newton and Amponsah (2007) described these models as important in product recovery, value estimation, stand structural analyses, growth and yield projection systems, and carbon budgeting models.

The $h-d$ relationship varies from stand to stand, and even within the same stand the relationship is not constant over time (Curtis, 1967). Therefore a single curve cannot be used to estimate all the possible $h-d$ relationships that can be found within a forest (Castedo Dorado et al., 2006). The most widely used method, which minimises this level of variance, is to estimate $h-d$ regressions for each plot and measurement occasion. If sufficient data are not available for these regressions, an $h-d$ model that includes stand variables that account for the special characteristics of each stand is often used (Curtis, 1967; Larsen and Hann, 1987; Temesgen and Gadow, 2004). 
It is frequently argued that the scatter plot of $h$ against $d$ reveals a sigmoid curve over the full range of diameters. In accordance with this, Niklas (1995) generalized (from his study on Robinia pseudoacacia) that growth in tree height is asymptotic and essentially definite. Researchers have since tested numerous nonlinear functions to model the $h-d$ relationship on the basis of this biological phenomenon. Fang and Bailey (1998) investigated the performance of 33 functions to develop $h-d$ models for diverse tree species of tropical forest on Hainan Island and selected a modified form of the exponential model (Meyer, 1940). In a crossvalidation study of six nonlinear growth functions for modelling $h-$ $d$ relationship for ten conifer tree species, Zhang (1997) concluded that Bertalanffy-Richards (Bertalanffy, 1949, 1957; Richards, 1959), Weibull-type (Yang et al., 1978), and Schnute (Schnute, 1981) functions provided more accurate results than other models. Peng (1999) also fitted 25 nonlinear $h-d$ model forms for nine tree species and reached a similar conclusion to Zhang (1997). Huang et al. (2000) evaluated 27 functions for modelling the $h-d$ relationship of white spruce grown in Alberta's boreal forests and concluded that the logistic-type function produced the most satisfactory fit. According to Yuancai and Parresol (2001), the Schnute function and the Bertalanffy-Richards function are probably the most flexible and versatile functions available for modelling $h-d$ relationships. Peng et al. (2001) also found the Bertalanffy-Richards, Weibull and Schnute functions to be superior to other models as regards prediction performance.

The hierarchical structure in the $h-d$ data (i.e., trees within plots within stands), usually results in a lack of independence among measurements, since observations from the same sampling unit may be highly correlated (West et al., 1984; Gregoire, 1987). Mixed model techniques have been used successfully (e.g., Lappi, 1997; Calama and Montero, 2004; Castedo Dorado et al., 2006) to deal with this problem. These models estimate both fixed and random parameters simultaneously for the same model, and allow the variability detected for given phenomena among different locations to be modelled after defining a common fixed functional structure (Lindstrom and Bates, 1990). This characteristic makes mixed-effects models more efficient when a prediction for a new individual is required and prior information is available (Trincado et al., 2007).

The main objective of the present study was to develop a model relating diameter at breast height and total height for Tasmanian blue gum growing in Galicia, on the basis of data from the Spanish National Forest Inventory. The particular nature of the circular plots used in this inventory, in which trees were sampled within different radii according to their diameter at breast height, obliged us to use a special technique to account for the unequal selection probability of each tree. Use of an $h-d$ relationship, a disaggregation system and a taper function enabled volume classification by merchantable sizes, and this will become important tools for the sustainable management of the species in the study area.
Table 1

Characteristics of the Spanish National Forest Inventory (SNFI) plots.

\begin{tabular}{rlllll}
\hline Plot radius $(\mathrm{m})$ & $\begin{array}{l}\text { Minimum } d \\
\text { threshold }(\mathrm{cm})\end{array}$ & $p_{i j}$ & $1 / p_{i j}$ & Fexp $i j$ & $R F e x p_{i j}$ \\
\hline 5 & 7.5 & 0.04 & 25 & 127.3 & 3.092 \\
10 & 12.5 & 0.16 & 6.25 & 31.83 & 0.7731 \\
15 & 22.5 & 0.36 & 2.778 & 14.15 & 0.3436 \\
25 & 42.5 & 1 & 1 & 5.093 & 0.1237 \\
\hline
\end{tabular}

$p_{i j}$ : selection probability of the $i$ th tree in the $j$ th plot, depending on its diameter, relative to that of the largest radius plot; $F e p_{i j}$ : hectare expansion factor (inverse of the selection probability on a per hectare basis); and $R F \exp _{i j}$ : rescaled expansion factor.

\section{Methodology}

\subsection{Data}

Data from the Second (ICONA, 1993) and Third (DGCONA, 2001, 2002a, 2002b) Spanish National Forest Inventory (SNFI) in Galicia (northwest Spain) were used to develop the $h-d$ model (Table 1 ). The SNFI is a systematic sample of circular combined sample plots (Loetsch et al., 1973), distributed on a square grid of $1 \mathrm{~km}$, with a remeasurement interval of 10 years. In each plot and for each measurement occasion, species, $d$ and $h$ are recorded for each sample tree over $7.5 \mathrm{~cm}$, along with tree quality and shape, and other variables. All plots with more than $90 \%$ Tasmanian blue gum stems were selected for the present study (1518 plots). The number of stems per hectare $\left(N_{j}\right)$ and stand basal area $\left(G_{j}\right)$ were calculated with all trees in the $j$ th plot. However, the mean height $\left(\bar{h}_{j}\right)$ was only calculated for Tasmanian blue gum trees, and dominant diameter $\left(\right.$ ddom $\left._{j}\right)$ and dominant height $\left(\right.$ hdom $\left._{j}\right)$ were calculated with the proportion of the 100 thickest healthy Tasmanian blue gum trees (unforked and with no apparent damage) per hectare. Some outliers were observed in the dataset, but as they represented only a minor percentage (less than $0.2 \%$ ), they were omitted from the analysis. Some plots (15) showed an illogical $h-d$ tendency (larger $h$ for smaller $d$ ), and so were not used. Excessively open plots were not used in this study either. The Hart index (i.e., $100 /\left(\right.$ hdom $\left._{j} N_{j}^{1 / 2}\right)$ ) was used as a criterion for distinguishing the competition level within each plot. A Hart index value of 50 was subjectively selected as the limit for considering that trees start to grow in competition-free conditions. This resulted in the elimination of 278 plots and 656 trees. It should be mentioned that the SNFI is a systematic sample, in which open plots, or plots with outliers, usually correspond to trees planted in lines at the edge of agricultural land. Despite the reduction in data, some quite open stands were still included (Table 2), so that the developed model would be useful for a wide variety of stand conditions. A total of 26117 pairs of $h-d$ measurements, taken from 417 plots from the second SNFI and from 808 plots from the third SNFI were finally used to fit the models. Summary statistics of the

Table 2

Summary statistics of the fitting and the validation datasets.

\begin{tabular}{|c|c|c|c|c|c|c|c|c|}
\hline \multicolumn{5}{|c|}{ Fitting dataset (26117 trees in 1225 plots) } & \multicolumn{4}{|c|}{ Validation dataset (475 trees in 88 plots) } \\
\hline Variable & Mean & Min. & Max. & Std. dev. & Mean & Min. & Max. & Std. dev. \\
\hline$d_{i j}(\mathrm{~cm})$ & 14.4 & 7.5 & 85.9 & 6.8 & 19.6 & 5.0 & 80.5 & 12.4 \\
\hline$h_{i j}(\mathrm{~m})$ & 16.7 & 3.0 & 51.0 & 5.9 & 19.8 & 5.0 & 46.6 & 8.3 \\
\hline$N_{j}\left(\right.$ stems ha $\left.^{-1}\right)$ & 895 & 41 & 2744 & 504 & & & & \\
\hline$G_{j}\left(\mathrm{~m}^{2} \mathrm{ha}^{-1}\right)$ & 17.8 & 1.8 & 85.7 & 11.5 & & & & \\
\hline$d g_{j}(\mathrm{~cm})$ & 16.5 & 8.3 & 51.6 & 5.6 & & & & \\
\hline ddom $_{j}(\mathrm{~cm})$ & 24.6 & 8.7 & 58.3 & 8.5 & 24.8 & 6.6 & 62.6 & 9.9 \\
\hline $\bar{h}_{j}(\mathrm{~m})$ & 17.0 & 5.9 & 43.2 & 4.6 & & & & \\
\hline $\operatorname{hdom}_{j}(\mathrm{~m})$ & 21.9 & 8.0 & 43.2 & 6.8 & 22.4 & 6.4 & 38.8 & 8.0 \\
\hline
\end{tabular}

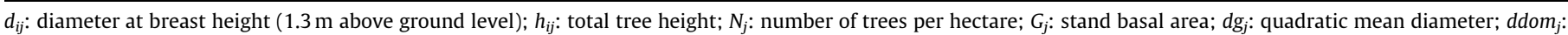
dominant diameter; $\bar{h}_{j}$ : mean height; and hdom $_{j}$ : dominant height. 
selected plots are shown in Table 2. From these plots, $21 \%$ were visually classified by the SNFI field staff as even-aged, $73 \%$ as uneven-aged, and the remaining plots were not classified. In addition, $27 \%$ of the plots were classified as seeded or planted, $8 \%$ as coppice, $59 \%$ as a composed coppice, and the remaining plots were not classified.

An independent dataset was used for validation purposes. This consisted of data from an inventory carried out in Galicia in 2008 by CELPA (Portuguese Pulp and Paper Industry Association). Plots ranged in size from 253 to $500 \mathrm{~m}^{2}$. Diameter at breast height was measured in all trees larger than $5 \mathrm{~cm}$ and total tree height was measured in dominant trees as well as in one representative tree per diameter class of $5 \mathrm{~cm}$ in each plot. The $h-d$ pairs plus the area of the plots comprised the input data. The data used for validation corresponded to representative trees in each diameter class (475 trees in 88 plots; $41 \%$ installed in uneven-aged and $59 \%$ in evenaged pure Tasmanian blue gum stands). Summary statistics of this dataset are shown in Table 2 .

\subsection{Methods}

\subsubsection{Expansion factors and stand variables}

The special inventory design of the SNFI, in which each plot is composed of four circular sub-plots with the same centre and different radii and minimum diameter threshold, determines that each tree $i$ in each plot $j$ has an unequal selection probability $\left(p_{i j}\right)$ (Table 1). Although this unequal selection probability scheme was mainly chosen for cost and administrative reasons, the hierarchical population structure underlying such schemes is of interest from a modelling point of view. It is usually argued that when the sample selection probabilities are related to the response variable even after conditioning on covariates of interests, the conventional estimators of the model parameters may be (asymptotically) biased (Kish, 1992; Pfeffermann et al., 1998). In such cases, weighted regression analysis with the weighting factor equal to the inverse of the selection probability $\left(w_{i j}=1 / p_{i j}\right)$ leads to unbiased estimations (Kish, 1992; Pfeffermann et al., 1998). In this study, if the selection probability is not taken into account during the fitting process, a biased estimation of the real population $h-d$ relationship towards larger diameter trees is obtained.

The basic idea of weighting for unequal selection probabilities is that if each observation is weighted with the inverse of the selection probability, we obtain the same results as if we have measured all the trees in a specific area. This can be easily seen by assuming that our "population" consists of all the trees in a hectare (calculated by replicating each single tree as many times as indicated by its expansion factor $F \exp _{i j}$, i.e., the quotient between a hectare and the area of the sub-plot in which a tree is included; Table 1). Linear or nonlinear regression can then be applied to this expanded data. By applying the same regression model to the SNFI data-type, and using weighted regression, with $\operatorname{Fexp}_{i j}$ as the weighting factor, the same parameter estimates are obtained. The same results are obtained when all the weighting factors are multiplied by a constant, so that they can be calculated on the basis of any per unit area, all providing unbiased estimates of the real population $h-d$ relationship parameters. The problem here is to choose the correct weighting factor, because the "real" population is unknown and comparison with the "real" value cannot be done.

It should be noted that when the data used to fit the models is "artificially" modified (by weighing), the approximate standard errors of the coefficients will also be affected. The general expression for correct calculation for the standard errors is:

Approx Std Error true $=$ Approx Std Error weight $\times \sqrt{\frac{N_{\text {weight }}-p}{N_{\text {true }}-p}}$ where $N_{\text {wejght }}$ is the number of observations used to fit the models, $N_{\text {true }}=\sum_{i=1}^{N_{\text {weight }}} w_{i j}$, and $p$ is the number of model parameters.

With the available information, the most logical methodology appears to be to rescale the weighting factors $\left(R_{F e x p}\right)$ so that the sum of the weights is equal to the number of observations used to fit the models (i.e., $R F \exp _{i j}=\operatorname{Fexp}_{i j} \times N_{\text {weight }} / N_{\text {true }}$; here $N_{\text {true }}=\sum_{i=1}^{N_{\text {weight }}} F \exp p_{i j}$, which means that the same number of observations are used to calculate the approximate standard errors as in model fitting. The RFexp $_{i j}$ weighting factors were used in this study, thus directly providing the approximate standard errors for the coefficients in the model fitting. However, the per hectare Fexp is also necessary, because it is used to calculate other variables that are usually expressed on a per hectare basis:

$N_{j}=\sum_{i=1}^{i=n_{j}} F \exp p_{i j}$

$G_{j}=\frac{\pi}{4} \sum_{i=1}^{i=n_{j}} d_{i j}^{2} F \exp p_{i j}$

$d g_{j}=100 \sqrt{\frac{4 G_{j}}{\pi N_{j}}}$

$\operatorname{ddom}_{j}=\frac{\sum_{i=1}^{i=n_{0 j}} d_{i j} F e x p_{i j}}{100}$

$\bar{h}_{j}=\frac{\sum_{i=1}^{i=n_{j}} h_{i j} \operatorname{Fexp} p_{i j}}{\sum_{i=1}^{i=n_{j}} \operatorname{Fexp}_{i j}}$

hdom $_{j}=\frac{\sum_{i=1}^{i=n_{0 j}} h_{i j} \operatorname{Fexp}_{i j}}{100}$

where $n_{j}$ is the number of trees in the $j$ th plot, $d_{i j}$ is the diameter at breast height ( $\mathrm{cm}, 1.3 \mathrm{~m}$ above ground level) of the $i$ th tree in the $j$ th plot, $d g_{j}$ is the quadratic mean diameter of the $j$ th plot $(\mathrm{cm}), n_{0 j}$ is the necessary number of trees in the $j$ th plot (selected in $d_{i j}$ descending order) for which the sum of their $\mathrm{Fexp}_{i j}$ is $100, h_{i j}$ is the height $(\mathrm{m})$ of the $i$ th tree in the $j$ th plot, and the other variables are as previously defined.

\subsubsection{Modelling fixed effects response}

In a first step, 25 generalized $h-d$ models selected from previous studies (Krumland and Wensel, 1988; Tomé, 1989; López Sánchez et al., 2003; Sharma and Zhang, 2004; Castedo Dorado et al., 2006; Sharma and Parton, 2007) were fitted to the dataset. Some modifications of the models were also tested (i.e., changing $d g_{j}$ and $\bar{h}_{j}$ to $d_{d o m}$ and $h d o m_{j}$, respectively). These models included the most flexible equations for $h-d$ relationships (i.e., the BertalanffyRichards, Weibull and Schnute models). Models that require age or site index were not used, or were modified to exclude these variables, as the age of most plots was unknown, and thus the site index model developed for Tasmanian blue gum in Galicia (García and Ruiz, 2003) could not be used.

For initial selection the above-mentioned models were fitted by weighted nonlinear least squares, without considering random parameters, with $R F e^{2} p_{i j}$ as the weighting factor. Different initial values for the parameters were used to ensure that a global minimum was achieved.

Weighting factors can be used to balance error variance, to account for non-normality and to take into account unequal selection probabilities. However, the residuals did not show any pattern of non-constant variance and, therefore weighting was only carried out to account for unequal selection probabilities and for non-normality. Calculation of the weighting factors to account 
for non-normality involves a two-stage fitting procedure. In the first stage the model is fitted with RFexp $_{i j}$ as the weighting factor. The next step is to "weight down" the influence of data points that produce large residuals (Myers, 1990, p. 348). This was done by using Huber's (1973) influence function (Myers, 1990, pp. 349350), and testing different values for the bounds of the function in order to obtain a normal probability plot of the residuals with a distribution as a straight line following the normal density function (e.g., Soares and Tomé, 2002). Large residuals were weighted by the bound value divided by the absolute value of the residual $\left(H_{i j}\right)$.

Statistical and graphical analyses were used to compare the performance of the models. Four statistical criteria obtained from the residuals were examined: the root mean square error (RMSE); the coefficient of determination $\left(R^{2}\right)$; the mean bias $(\bar{E})$; and Schwarz's Bayesian Information Criteria (BIC; Schwarz, 1978) under squared error loss. In order to calculate the real value of these statistics (i.e., the value which would be obtained if all the trees in the $25 \mathrm{~m}$ radius plot were measured), the weighting factor must be included in the formulation, resulting in:

RMSE $=\sqrt{\frac{\sum_{i=1}^{i=N_{\text {weight }}} R F e x p_{i j} \times\left(Y_{i j}-\hat{Y}_{i j}\right)^{2}}{N_{\text {true }}-p}}$

$R^{2}=1-\frac{\sum_{i=1}^{i=N_{\text {weight }}} R F e x p_{i j} \times\left(Y_{i j}-\hat{Y}_{i j}\right)^{2}}{\sum_{i=1}^{i=N_{\text {weight }}} R F e x p_{i j} \times\left(Y_{i j}-\bar{Y}\right)^{2}}$

$\bar{E}=\frac{\sum_{i=1}^{i=N_{\text {weight }}} R F e x p_{i j} \times\left(Y_{i j}-\hat{Y}_{i j}\right)}{N_{\text {true }}}$

$\mathrm{BIC}=N_{\text {true }} \times \ln \left(\frac{\sum_{i=1}^{i=N_{\text {weight }}} R F e x p_{i j} \times\left(Y_{i j}-\hat{Y}_{i j}\right)^{2}}{N_{\text {true }}-p}\right)$

$+p \ln N_{\text {true }}$

where $Y_{i j}, \hat{Y}_{i j}$ and $\bar{Y}=\sum_{i=1}^{i=N_{\text {weight }}} R F e x p_{i j} \times Y_{i j} / N_{\text {true }}$ are the measured, estimated and average values of the dependent variable, respectively, and $p$ is the number of model parameters.

Using these statistical criteria, and visual analysis of plots of residuals against predicted values as helpful tools to identify lack of fit, the best models were selected for further analysis.

\subsubsection{Modelling mixed effects}

Detailed information on nonlinear mixed-effects modelling for $h-d$ relationships are provided by Calama and Montero (2004) and Castedo Dorado et al. (2006). General information and discussion on nonlinear mixed models in the forestry context can be found in Hall and Bailey (2001). Finally, the multilevel case of mixed models has been discussed by several authors in a general context (e.g., Lindstrom and Bates, 1990; Longford, 1993; Goldstein, 1995). Basically the parameter vector of the nonlinear model can be defined as (Pinheiro and Bates, 1998):

$\boldsymbol{\Phi}_{j}=\mathbf{A}_{j} \lambda+\mathbf{B}_{j} \mathbf{b}_{j}$

where $\lambda$ is the $p \times 1$ vector of fixed population parameters (where $p$ is the number of fixed parameters in the model), $\mathbf{b}_{j}$ is the $q \times 1$ vector of random effects associated with the $j$ th plot (where $q$ is the number of random parameters in the model), and $\mathbf{A}_{j}$ and $\mathbf{B}_{j}$ are design matrices of size $r \times p$ and $r \times q$ (where $r$ is the total number of parameters in the model) for the fixed and random effects specific to each plot, respectively. Basic assumptions for the nonlinear mixed-model theory include the asymptotic multivariate normal distribution for the random effects vector, the residual terms vector and the observations of the response variable vector.
A special structure for the within-plot variance-covariance matrix $\mathbf{R}_{j}\left(\lambda, \mathbf{b}_{j}, \rho\right)$ (which is allowed to depend on both random and fixed effects, as well as on a set of common but unknown parameters $\rho$ ) can be proposed to include both correlation effects and weighting factors (Calama and Montero, 2004). As explained before, only weighting factors accounting for non-normality and unequal selection probabilities were used. In this case a general expression for the matrix is given by (Calama and Montero, 2004):

$\mathbf{R}_{j}\left(\boldsymbol{\lambda}, \mathbf{b}_{j}, \boldsymbol{\rho}\right)=\sigma^{2} \mathbf{G}_{j}^{0.5} \mathbf{I}_{j} \mathbf{G}_{j}^{0.5}$

where (in this case) for a plot $j$, with $n_{j} h-d$ measurements, $\mathbf{G}_{j}^{0.5}$ is a $n_{j} \times n_{j}$ diagonal matrix including the root square of the inverse of the weights $\left(\left[1 /\left(\operatorname{RFexp}_{i j} \times H_{i j}\right)\right]^{0.5}\right)$ as elements, $\mathbf{I}_{j}$ is a $n_{j} \times n_{j}$ identity matrix, and $\sigma^{2}$ is a scaling factor for the error dispersion (Gregoire et al., 1995).

The SAS macro NLINMIX (Litell et al., 2006) was used to fit the models, and maximization of the marginal likelihood function was achieved using the best linear unbiased predictor (BLUP) approximation (Beal and Sheiner, 1982). The two-stage approach, for selecting weights to account for non-normality, was used.

Different combinations of parameters were assumed to be mixed (composed of a fix part, common to every plot, and a random part, specific to each plot). The models in which convergence was met were compared in terms of the previously mentioned statistics and residual plots.

\subsubsection{Calibrated response}

An advantage of mixed-effects models is that if a subsample of $k$ tree heights is available, such data can be used to predict the random effects vector $\mathbf{b}_{j}$, with the following expression (Vonesh and Chinchilli, 1997):

$\hat{\mathbf{b}}_{j} \approx \hat{\mathbf{D}} \hat{\mathbf{Z}}_{j}^{\mathrm{T}}\left(\hat{\mathbf{R}}_{j}+\hat{\mathbf{Z}}_{j} \hat{\mathbf{D}} \mathbf{Z}_{j}^{\mathrm{T}}\right)^{-1} \hat{\mathbf{e}}_{j}$

where $\hat{\mathbf{D}}$ is a $q \times q$ unstructured (in this case) variance-covariance matrix for the among-plot variability, common to all plots and estimated in the general fitting of the model; $\hat{\mathbf{R}}_{j}$ is the $k \times k$ variance-covariance matrix for within-plot variability; $\hat{\mathbf{e}}_{j}$ is the residual vector $k \times 1$, the components of which are given by the difference between the observed height value for each tree included in the subsample, and the value predicted by the model including only fixed effects; and $\hat{\mathbf{Z}}_{j}$ is the $k \times q$ matrix of partial derivatives evaluated at $\hat{\mathbf{b}}_{j}$. Once $\hat{\mathbf{b}}_{j}$ is predicted, the value of the vector of heights, i.e., the calibrated response vector, can be calculated with the general expression of the parameter vector of the nonlinear model (Eq. (12)).

If we wish to predict heights of a particular stand with no prior $h-d$ observations, the fixed effects typical response should be used, considering that the best linear unbiased predictor of $\mathbf{b}_{j}$ is the null $q \times 1$ vector, i.e., $\hat{\boldsymbol{\Phi}}_{j}=\mathbf{A}_{j} \hat{\lambda}$.

For the best model, the calibrated response was evaluated for different height sampling designs and sampling sizes within each plot, by randomly selecting 123 plots (10\% of the total number of plots used to fit the models) and using the remaining plots for estimating $\hat{\lambda}$ and $\hat{\mathbf{D}}$. The alternatives selected were:

(i) Total height of 1-10 randomly selected trees per plot.

(ii) Total height of 1-10 largest trees per the plot.

(iii) Total height of 1-10 smallest trees per the plot.

(iv) Total height of 1-10 medium-size trees per plot.

(v) Total height of 3, 6 and 9 trees per plot, in the largest, smallest and medium-size categories.

$\hat{\mathbf{b}}_{j}$ was then calculated for each of the 123 plots. The calibrated $h-d$ model was then applied to all the trees in each of these plots. The five alternatives were evaluated in terms of the previously defined statistics (RMSE, $R^{2}$ and), and compared with the $\bar{E}$ estimations 
obtained with ordinary nonlinear least squares (ONLS) in the individual fit of the selected model to each of the calibration plots. For the randomly selected trees, mean values of the statistics after 100 simulations were obtained.

\subsubsection{Validation}

Ordinary residuals are measures of quality of fit and do not assess the quality of estimates for other data (Myers, 1990, p. 168). Only validation using newly collected data will give some indication of the precision of the model (Kozak and Kozak, 2003; Huang et al., 2003). Thus validation was carried out with the above-mentioned independent dataset. For this purpose, the previously estimated model was applied to the independent dataset, and the RMSE, $R^{2}$ and $\bar{E}$ statistics, plus plots of residuals and observed values versus predicted values, were calculated. As the validation dataset consisted of fixed-area plots, the weighting factor was the same for all trees, i.e., 1.

\section{Results}

The best results from the initial fitting were obtained with the following six models:

$$
\begin{aligned}
& \hat{h}_{i j}=1.3+a_{0} \operatorname{hdom}_{j}^{a_{1}}\left(1-\exp -\left(a_{2} \text { ddom }_{j}^{a_{3}} d_{i j}\right)\right)^{a_{4}} \\
& \hat{h}_{i j}=\operatorname{hdom}_{j}\left(1+a_{0} \exp \left(a_{1} \operatorname{ddom}_{j}\right)\right)\left(1-\exp \left(\frac{-a_{2} d_{i j}}{\text { ddom }_{j}}\right)\right)
\end{aligned}
$$

$\hat{h}_{i j}=1.3+\left(\right.$ hdom $\left._{j}-1.3\right) \frac{\exp \left(a_{0} d_{i j}^{\rightleftarrows a_{1}+a_{2}\left(\text { hdom }_{j}-1.3\right)}\right)}{\exp \left(a_{0} \text { ddom }_{j}^{a_{1}+a_{2}\left(\text { hdom }_{j}-1.3\right)}\right)}$

$\hat{h}_{i j}=1.3+($ hdom

- 1.3) $\exp \left(a_{0}\left(\frac{1-\text { ddom }_{j}}{d_{i j}}\right)+a_{1}\left(\frac{1}{\text { ddom }_{j}}-\frac{1}{d_{i j}}\right)\right)$

$\hat{h}_{i j}=d_{d o m_{j}} \exp \left(\left(\frac{a_{0}+a_{1} h_{d o m_{j}}+a_{2} N_{j}}{1000}\right)\left(\frac{1}{d_{i j}}-\frac{1}{\text { ddom }_{j}}\right)\right)$

$\hat{h}_{i j}=a_{0} \operatorname{hdom}_{j}\left(1-\exp \left(\frac{-a_{1} d_{i j}}{\text { ddom }_{j}}\right)\right)^{a_{2}}$

where $\hat{h}_{i j}$ is the predicted height ( $\mathrm{m}$ ) of the $i$ th tree in the $j$ th plot, $a_{0}$ to $a_{4}$ are the parameters to be estimated, and the other variables are as previously defined.

Eq. (15) is a modified version of the Bertalanffy-Richards model, which includes dominant height $\left(\right.$ hdom $\left._{j}\right)$ and dominant diameter $\left(d_{d o m}\right)$ in the formulation. A preliminary analysis showed that this model was superior to other proposed modifications of the original model (e.g., Sharma and Zhang, 2004; Sharma and Parton, 2007). Eq. (16) is a modified version of the model used by Harrison et al. (1986) in which hdom $_{j}$ is replaced by $d_{d o m}$ in two terms. Eq. (17) is a modification of the model used by Krumland and Wensel (1988), in which the constants and the variables have been transformed to SI units. Eq. (18) is a modification of the model used by Gaffrey (1988), in which the quadratic mean diameter $\left(d g_{j}\right)$ was changed to $d d o m_{j}$. Eq. (19) is a modification of the model used by Tomé (1989), in which the age term was omitted. Eq. (20) is a modification of the original model by Pienaar et al. (1990), in which the parameter associated with the number " $e$ " was omitted, the $d g_{j}$ was changed to $d_{d o m}$ and a new parameter was added as an exponent. All these models showed a good fit to the dataset, and explained more than $83 \%$ of the observed variability $\left(R^{2}\right)$, with RMSEs less than $2.5 \mathrm{~m}, \bar{E}$ values below $0.1 \mathrm{~m}$, and low BIC values. Residual plots indicated
Table 3

Goodness of fit statistics for the mixed effects generalized $h-d$ models. The values in brackets were calculated with the fixed part of the parameter estimates only.

\begin{tabular}{llllll}
\hline Equation & Random & $R^{2}$ & RMSE & $\bar{E}$ & BIC \\
\hline$(15)$ & $a_{1}, a_{4}$ & 0.8950 & 1.911 & -0.1009 & 33892 \\
& & $(0.8380)$ & $(2.375)$ & $(0.0890)$ & \\
$(16)$ & $a_{2}$ & 0.8847 & 2.003 & 0.0010 & 36326 \\
& & $(0.8343)$ & $(2.402)$ & $(-0.0247)$ & \\
$(17)$ & $a_{1}, a_{2}$ & 0.8902 & 1.954 & -0.0396 & 35083 \\
& & $(0.8418)$ & $(2.346)$ & $(0.0830)$ & \\
$(18)$ & $a_{1}$ & 0.8867 & 1.986 & -0.1259 & 35859 \\
& & $(0.8332)$ & $(2.409)$ & $(0.0656)$ & \\
$(19)$ & $a_{0}, a_{2}$ & 0.8874 & 1.980 & -0.0578 & 35724 \\
& & $(0.8386)$ & $(2.370)$ & $(-0.0289)$ & \\
$(20)$ & $a_{0}, a_{2}$ & 0.8944 & 1.917 & -0.1299 & 34047 \\
& & $(0.8366)$ & $(2.385)$ & $(0.0186)$ & \\
\hline
\end{tabular}

no lack of fit, and the QQ plots, after correction for non-normality, showed a linear tendency for the residuals.

The addition of random parameters that vary for each plot clearly improved the model fits (Table 3 ). The explained variability increased by $6.4 \%$, the RMSE decreased by $18 \%$, and the BIC decreased by, on average, 23\%. However, the $\bar{E}$ values only decreased for Eq. (16) and increased slightly for the rest of the equations.

Taking into account other characteristics not included in the goodness of fit statistics and residual plots, Eq. (15) was not selected, because although it showed the best values for the fitting statistics $R^{2}$ and RMSE, the values were only slightly better than for other models, and the model had the disadvantage of including more parameters; it can be seen that it is similar to Eq. (20), but with two more parameters. The bias was also slightly greater than in the other models. Another slight disadvantage of Eqs. (15), (16) and (20) is that they are not restricted to passing through the point $\left(\operatorname{ddom}_{j}, h_{d o m_{j}}\right)$. This is not very important from a modelling point of view, but is important in order to make the model compatible with other models in a simulation system (e.g., with a site index system). With two models of similar accuracy, the model including the latter variables is preferable, although this is not an exclusionary condition. Finally, the disadvantage of Eq. (19) was that it included the number of stems in the formulation, which is a problem from a practical point of view, as it predicts an instantaneous change in predicted height following thinning. Also, the lower limit of the diameter measurement (i.e., $7.5 \mathrm{~cm}$ in this study) has an important effect on the computed number of stems per hectare; this limit is quite variable for the species in the study area (usually between 5 and $10 \mathrm{~cm}$ ) and thus it is better to avoid this variable if possible (i.e., if there are other optional models with similar accuracy). As regards Eqs. (17) and (18), the former showed slightly better fitting statistic values. Thus, Eq. (17) was selected as the generalized $h-d$ relationship for Tasmanian blue gum in the study area, as it showed a good compromise between precision and accuracy for both the fixed effects and the mixed-effects model (Table 3 ). The mixed-effects model form of this equation is:

$$
\begin{aligned}
\hat{h}_{i j}= & 1.3+\left(\text { hdom }_{j}\right. \\
& -1.3) \frac{\exp \left(a_{0} d_{i j}^{\left(a_{1}+u_{j}\right)+\left(a_{2}+v_{j}\right)\left(\text { hdom }_{j}-1.3\right)}\right)}{\exp \left(a_{0} d d o m_{j}^{\left(a_{1}+u_{j}\right)+\left(a_{2}+v_{j}\right)\left(\text { hdom }_{j}-1.3\right)}\right)}+e_{i j}
\end{aligned}
$$

where $u_{j}$ and $v_{j}$ are random parameters, specific for plot $j, e_{i j}$ represents the estimation error for the $i$ th observation in the $j$ th plot, and the other variables are as previously defined. Parameter estimates for Eq. (21) are shown in Table 4. 
Table 4

Parameter estimates and approximated standard errors for the mixed effects generalized $h-d$ model selected for Tasmanian blue gum in Galicia (Eq. (21)).

\begin{tabular}{lll}
\hline Parameter & Estimate & Standard error \\
\hline$a_{0}$ & -7.914 & 0.148 \\
$a_{1}$ & -1.444 & 0.022 \\
$a_{2}$ & 0.02259 & 0.00075 \\
$\sigma_{u}^{2}$ & 0.1512 & 0.0184 \\
$\sigma_{v}^{2}$ & 0.0001244 & 0.0000261 \\
$\sigma_{u v}$ & -0.004188 & 0.000698 \\
$\sigma^{2}$ & 2.561 & 0.230 \\
\hline
\end{tabular}

The Huber's (1973) influence function finally used was:

$H_{i j}=\left\{\begin{array}{lll}2 / a b s(\text { residual }) & \text { if } & \text { residual }<-2 \\ 1 & \text { if } & -2 \leq \text { residual } \leq 3 \\ 3 / a b s(\text { residual }) & \text { if } & \text { residual }>3\end{array}\right\}$

Using this function the residuals followed a normal distribution as shown in the QQ plots before and after correction for nonnormality (Fig. 1).

The parameter estimates and goodness of fit statistics for Eq. (21), fitted without weighting factors to account for unequal
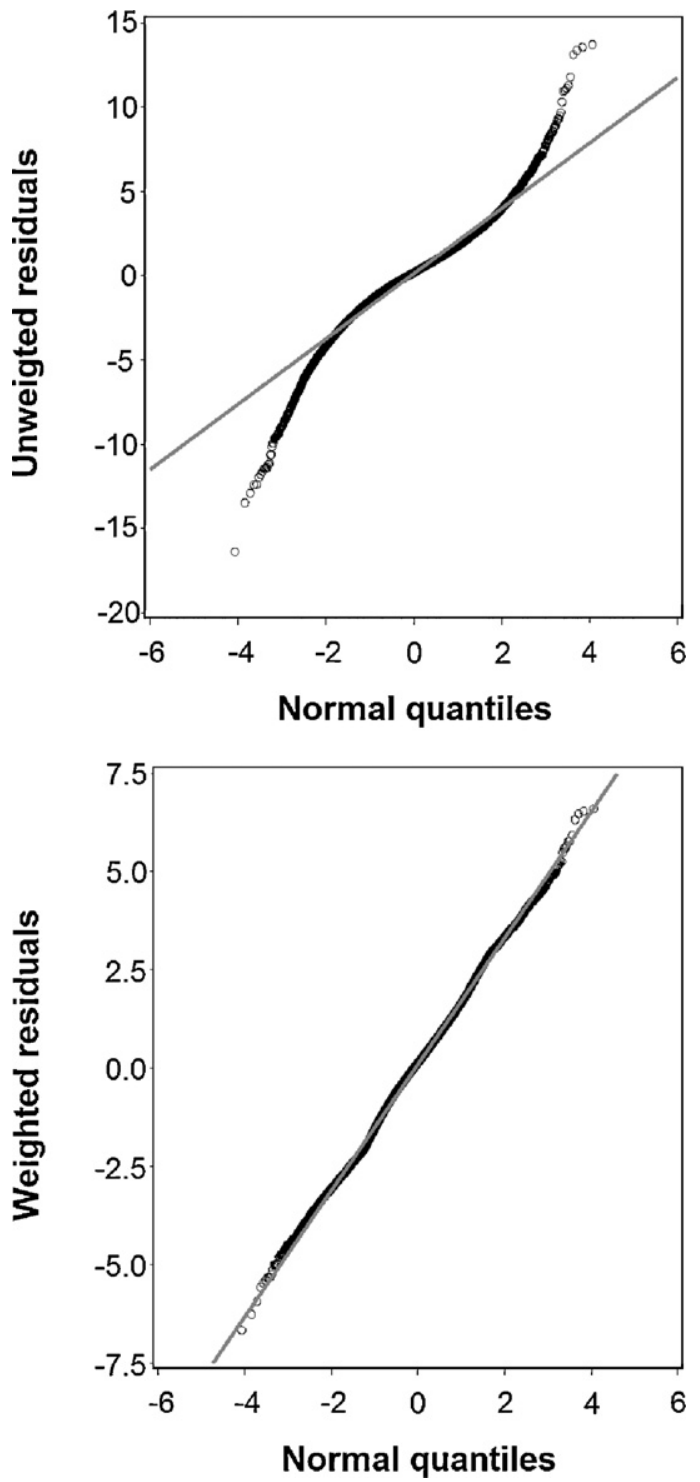

Fig. 1. QQ plots before and after correction for non-normality for Eq. (21).
Table 5

Parameter estimates, approximate standard errors and goodness of fit statistics for the mixed effects generalized $h-d$ model selected for Tasmanian blue gum in Galicia (Eq. (21)), without including weights to account for unequal selection probabilities. The values in brackets were calculated with the fixed part of the parameter estimates only.

\begin{tabular}{lllcccc}
\hline Parameter & Estimate & Standard error & $R^{2}$ & RMSE & $\bar{E}$ & BIC \\
\hline$a_{0}$ & -8.967 & 0.225 & 0.8875 & 2.398 & 0.1760 & 45731 \\
$a_{1}$ & -1.453 & 0.025 & $(0.8568)$ & $(2.705)$ & $(0.2517)$ & \\
$a_{2}$ & 0.02091 & 0.00080 & & & & \\
$\sigma_{u}^{2}$ & 0.1253 & 0.0216 & & & & \\
$\sigma_{v}^{2}$ & 0.00008950 & 0.00003041 & & & & \\
$\sigma_{u v}$ & -0.003182 & 0.0008134 & & & & \\
$\sigma^{2}$ & 4.051 & 0.036 & & & & \\
\hline
\end{tabular}

selection probabilities, are shown in Table 5 . As can be seen, the impact of the weighting procedure is minimal, and the parameter estimates and approximate standard errors are of the same magnitude. The goodness of fit statistics are also similar, with slightly better values for the model fitted taking into account the unequal selection probabilities.

The results of the calibrated response pattern (Fig. 2) showed that the largest values of RMSE were obtained when applying the fixed effects response model, without predicting random parameters. In contrast, individual fitting with weighted nonlinear least squares produced the smallest value, because it is the best possible fit of the function for each plot. The greatest reduction in RMSE in the calibration response was obtained with data from the smallest trees in the plot. Use of the three smallest trees in the plot led to reduction of the RMSE by $26 \%$, and reduction of the bias by $45 \%$ relative to the fixed effects response. When the largest trees in the plot are used, the sample must be large (more than five trees) to reduce the RMSE values relative to the fixed effects response. Finally, with randomly selected trees, medium-size trees, or a mixture of trees selected from the smallest, medium and largest size classes, the reduction in RMSE was smaller than in the case of selection of the smallest trees.

As regards validation, the statistics for the fixed effects response showed good results, with a $R^{2}=0.8835$, a RMSE $=2.839 \mathrm{~m}$, and a $\bar{E}=0.3462 \mathrm{~m}$. For the mixed effects calibrated response in which the tree sampled in the smallest diameter class in each plot was used to calculate the random effects vector, the bias was greatly reduced $(-0.02896 \mathrm{~m})$, with a small increase in $R^{2}(0.8911)$ and a small decrease in RMSE $(2.751 \mathrm{~m})$. The curves also provided better predictions when the calibrated response was used (Fig. 3), particularly for the smallest trees.

\section{Discussion}

From a total of $25 h-d$ models tested in this study, the equations that showed the best fit to the dataset included dominant diameter and dominant height in their formulation. In general, the inclusion of stand variables in a local $h-d$ model reduces bias and increases precision (e.g., Soares and Tomé, 2002; Calama and Montero, 2004; Newton and Amponsah, 2007). Stand density is the most obvious factor affecting the $h-d$ relationship in a stand (Zhang et al., 1997; Zeide and Vanderschaaf, 2002): in dense stands, trees of the same diameter are usually taller than those in less dense stands. The inclusion of dominant diameter appeared to take into account the level of competition within the stand (Castedo Dorado et al., 2006). As already mentioned, Eq. (19) includes the number of stems per hectare in its formulation, resulting in prediction of instant changes in estimated height following thinning. Although the remainder of the equations also suffer variation in the estimates if $h d o m_{j}$ or $d_{d o m_{j}}$ change, these variables usually remain constant after thinning (except for thinning from above), and are thus more 

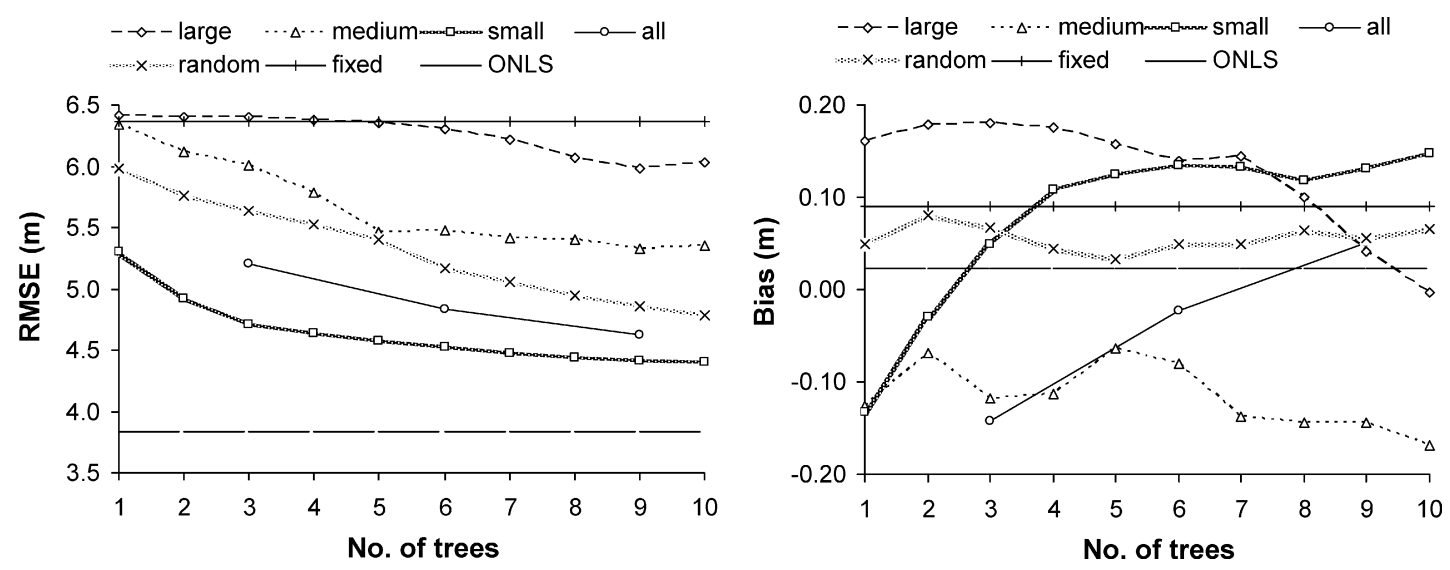

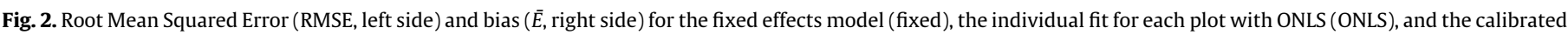

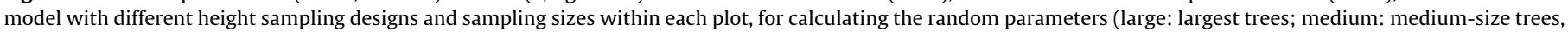
small: smallest trees; all: a mixture of large, medium and small trees; random: randomly selected trees).
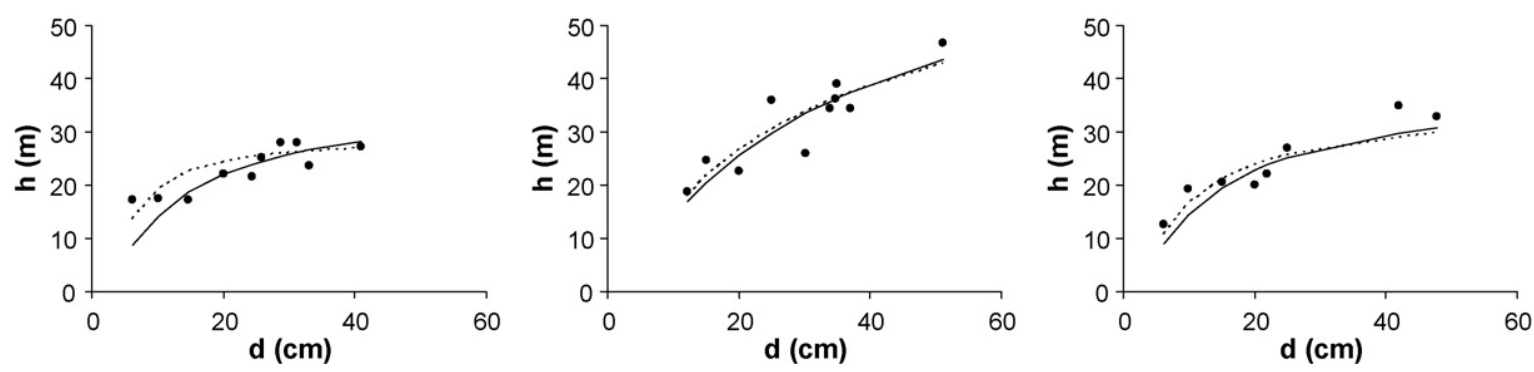

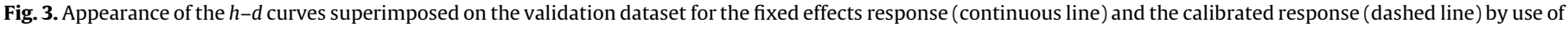
the tree sampled in the smallest diameter class in each plot to calculate the random effects vector, for three particular plots.

realistic. Tasmanian blue gum stands suffer from a lack of management in the study area, and thinning is not usually carried out. However, the recent increase in the area forested with this species, and the stabilization of timber demand for purposes such as pulp and fibre boards, make it necessary to search for new silvicultural schemes with high quality wood production in mind. In such schemes, thinning is one of the most important treatments to be applied. The possibilities of such production are realistic in the most productive sites in the study area (Nutto and Touza Vázquez, 2004).

Dominant height has also previously been included in similar models by many authors (e.g., Eerikäinen, 2003; Castedo Dorado et al., 2005; Adame et al., 2008). In the present study, models that included dominant height provided more accurate results than those including mean height. This may be advantageous, since fewer trees need to be measured to estimate dominant height than to estimate mean height (unless the mean height is obtained as the height of the average diameter tree, which is, on the other hand, a less accurate way of obtaining the mean height), and this great sampling effort may limit future use of the model (López Sánchez et al., 2003).

Eq. (21) is based on the model proposed by Krumland and Wensel (1988), which has been used successfully in other studies (e.g., Hanus et al., 1999), although for even-aged stands. As the age of most of the stands was unknown in the present study, and the intention was to develop a model applicable to a wide variety of situations, dominant diameter and dominant height were calculated in the same way in all stands (the average diameter and height of the largest diameter Tasmanian blue gum trees, respectively). As can be seen from the results and goodness of fit statistics, this makes sense for the dataset used, and makes the range of applicability of the model wide enough for the Galician
Tasmanian blue gum population. An attempt was made to expand model parameters, with dummy variables, to account for differences between even- and uneven-aged stands, and also between different stand origins (i.e., seeded or planted, coppice or composed coppice). No differences were found, perhaps due to the high variability in the stand conditions used in the study, or to errors in the visual classification of the plots by the SNFI field staff.

The best results for the calibration were obtained by selecting the smallest trees in the plot. As noted by Castedo Dorado et al. (2006), who obtained similar results, this may be attributed to the fact that the dominant height of the plot was already considered as a fixed effect in the basic $h-d$ model and, therefore, heights corresponding to the largest trees did not provide much additional information for calibrations. In addition, the fact that the model is restricted to pass through the point $\left(d_{d o m_{j}}, h_{d o m}\right)$ implies that it cannot change much in this part of the $h-d$ relationship. In contrast, although measurement of the smallest trees per plot provides a biased sample, the accuracy was greater than that of the fixed effects model, and even in comparison with the calibrated model with the randomly selected trees. The greater the number of measurements included in the subsample, the greater the decrease in RMSE (Fig. 2) and increase in $R^{2}$. However, a large sample is not often justifiable because of the increased cost of sampling (Castedo Dorado et al., 2006). The model bias did not follow the same pattern. As the tested samples are biased, they tend to increase bias in some way. The only method that maintains bias at a low level is the random selection (Fig. 2). However, this procedure makes it necessary to repeat the selections, in order to avoid large errors if an inadequate tree is selected, and at least eight trees should be randomly selected for the same level of accuracy as achieved by selection of the two smallest trees in the plot. It should also be 
mentioned that as the results obtained for the random selection are the average of 100 simulations, they give a "better than real" evaluation, and the probabilities of having a result worse than this are high if only one repetition is carried out. Selection of the two or three smallest trees in the plot kept bias at a low level, and as already mentioned, produced the greatest reduction in RMSE relative to other selection methods.

Yuancai and Parresol (2001) stated that the three properties that should be considered for $h-d$ relationships were: (1) monotonic increment, (2) functional inflection point, and (3) asymptotic value. However, a sigmoid or S-shaped tendency (which included these three properties) was not detected in this study. In our opinion, a S-shaped tendency, as observed for example in a dominant height growth model, is not necessary in a $h-d$ relationship, as it only expresses the relationship between two variables at a given point in time, and not any trends in growth.

Comparison of the fitting statistics for weighted regression and ordinary regression would be interesting but was not possible in this study, because the "real" population was not available for comparisons. Parameter estimates, approximate standard errors and goodness of fit statistics do not differ very much for the given dataset (note that this is not the "real" population) using the weighting procedure to account for unequal selection probabilities and ordinary regression. However, as explained in the Section 2.2, the purpose of the weighting procedure is to obtain unbiased parameter estimates, and to develop a model that accurately reflects the true $h-d$ relationship of the population, and therefore it is necessary to use weighting regression and to include the weighting factors in the fitting statistics.

When the developed model is used, the weighting factors should only be taken into account when calculating random parameters (in the calibration) in inventory designs with unequal selection probabilities, because otherwise all the weighting factors are equal to 1 (i.e., all the trees have a selection probability of 1 ). In the case of using a unequal selection probability inventory design, the weighting factors that should be included in the calibration process are those rescaled to the same "area" used in the model fitting, which in this study was $242.87 \mathrm{~m}^{2}$ $\left(\left(10000 \times \quad N_{\text {true }} / N_{\text {weight }}=10000 \times 26117\right) / \sum_{i=1}^{26117} \mathrm{Fexp}_{i j}\right) . \quad$ An example of use of the calibrated model is shown in Appendix A. Use of large weighting factors in the trees selected for calibration results in better calibrated height prediction for these particular trees, because the large weighting factor means that these trees are "more important" than others in the "real" population.

\section{Conclusions}

Several generalized $h-d$ models were considered in this study for developing a $h-d$ model for E. globulus in Galicia (NW Spain). Those equations that included dominant height and dominant diameter in their formulation provided the best results. Models that include dominant height imply a low sampling effort, because they only require measurement of diameters and a small sample of heights (the dominant trees) for their practical application.

A mixed-model approach and weighting regression were used to estimate both fixed and random effect parameters for the $h-d$ functions. Weighted regression enabled estimation of unbiased parameters for the $h-d$ relationship. The inclusion of random effects specific to each plot allowed dealing with the lack of independence among observations derived from the special hierarchical structure of the data (trees within plots). The results showed that the mixed-effects model provided better model fitting and more precise estimations than the corresponding basic generalized model. Different alternative height sampling designs and sampling sizes for calibrating the generalized $h-d$ model for a particular plot of interest were also applied. For the experimental data analyzed, calibration can be used to obtain $h-d$ relationships tailored to individual plots by measuring only the height of the three smallest trees per plot, although the model also requires dominant height for implementation. The calibrated $h-d$ model allows accurate results to be obtained with a very small sampling effort, making this approach highly effective and useful.

Validation showed that the model can be applied with good results to other data, and also that the calibration procedure can be applied, even with the selection of one tree per plot, thus improving the predictions obtained with the $h-d$ model.

Eq. (21), with the parameter estimates shown in Table 4 , is proposed as the generalized $h-d$ relationship for E. globulus in Galicia.

\section{Acknowledgements}

The present study was completed during a stay by the first author at the Instituto Superior de Agronomia, Universidade Técnica de Lisboa (Lisbon, Portugal), financially supported by the Spanish Ministry of Science and Innovation.

We are grateful to CELPA (Portuguese Pulp and Paper Industry Association), who kindly provided the data used for model validation.

We also thank Cristina Díaz Rodríguez for invaluable collaboration and work at the beginning of this study, and Dr. Christine Francis for correcting the English grammar of the text. 


\section{Appendix A}

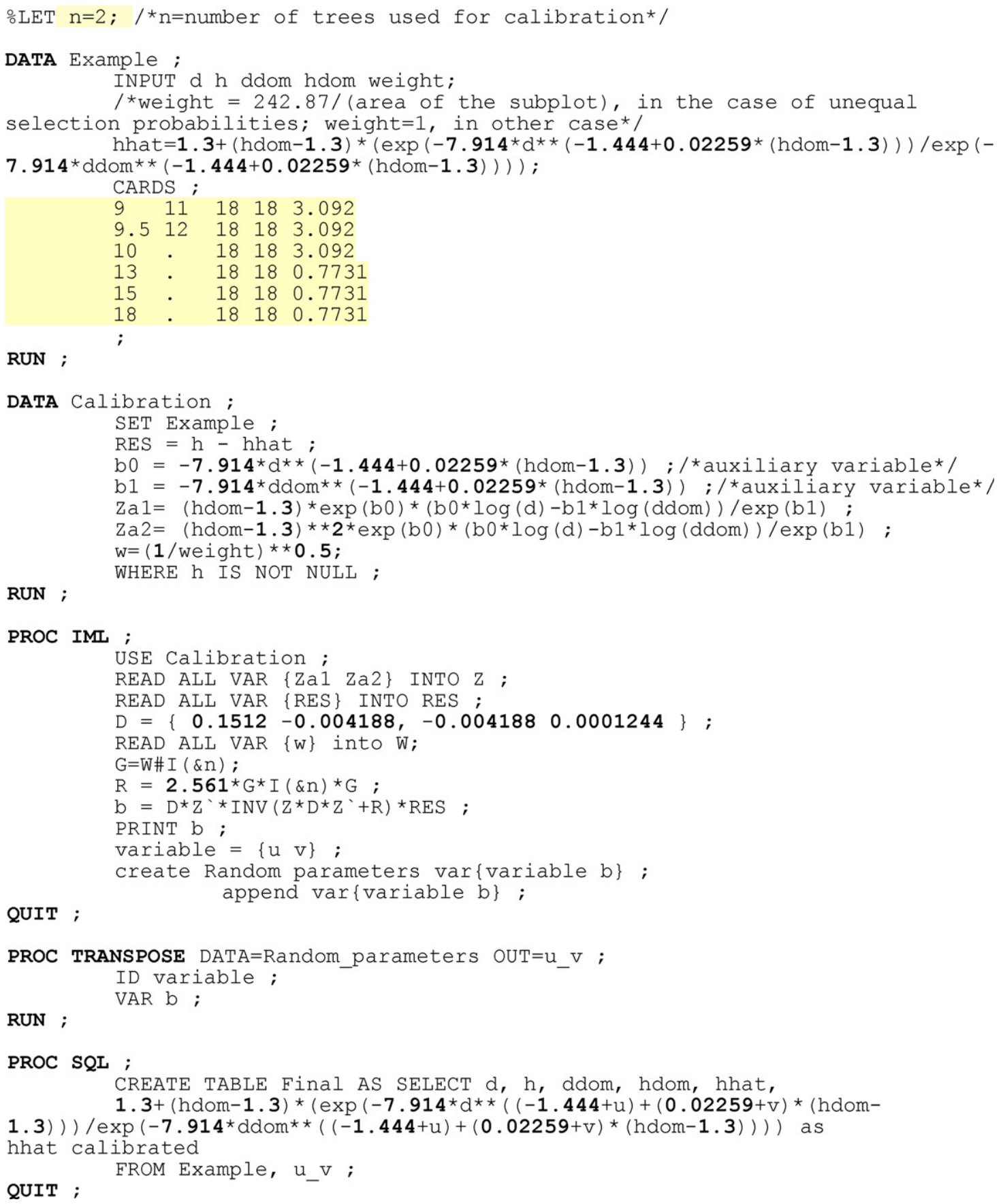

PROC IML

USE Calibration ;

READ ALL VAR \{Za1 Za2\} INTO Z;

READ ALL VAR \{RES\} INTO RES ;

PROC TRANSPOSE DATA=Random parameters OUT $=\mathrm{U} \mathrm{V}$;

ID variable ;

RUN ;

VAR b ;

PROC SQL ;

CREATE TABLE Final AS SELECT d, h, ddom, hdom, hhat,

$1.3+($ hdom -1.3$) *(\exp (-7.914 * d * *((-1.444+u)+(0.02259+v) *($ hdom -

1.3) ) ) $/ \exp (-7.914 *$ ddom** $((-1.444+\mathrm{u})+(0.02259+\mathrm{v}) *($ hdom -1.3$))))$ as

hhat calibrated

QUIT ;

FROM Example, u_v ;

\section{References}

Adame, P., del Río, M., Cañellas, I., 2008. A mixed nonlinear height-diameter mode for pyrenean oak (Quercus pyrenaica Willd.). Forest Ecology and Management 256, 88-98.

Beal, S.L., Sheiner, L.B., 1982. Estimating population kinetics. CRC Critical Reviews in Biomedical Engineering 8, 195-222.

Bertalanffy, L.v., 1949. Problems of organic growth. Nature 163, 156-158.

Bertalanffy, L.v., 1957. Quantitative laws in metabolism and growth. Quarterly Review of Biology 32, 217-231.

Calama, R., Montero, G., 2004. Interregional nonlinear height-diameter model with random coefficients for stone pine in Spain. Canadian Journal of Forest Research $34,150-163$.
Castedo Dorado, F., Barrio Anta, M., Parresol, B.R., Álvarez González, J.G., 2005. A stochastic height-diameter model for maritime pine ecoregions in Galicia (northwestern Spain). Annals of Forest Science 62, 455465.

Castedo Dorado, F., Diéguez-Aranda, U., Barrio Anta, M., Sánchez Rodríguez, M., Gadow, K.v., 2006. A generalized height-diameter model including random components for radiata pine plantations in northwestern Spain. Forest Ecology and Management 229, 202-213.

Curtis, R.O., 1967. Height-diameter and height-diameter-age equations for second-growth Douglas-fir. Forest Science 13, 365-375.

DGCONA, 2001. Tercer Inventario Forestal Nacional, 1997-2006. Galicia, A Coruña. Dirección General de Conservación de la Naturaleza, Ministerio de Medio Ambiente, Madrid, $371 \mathrm{pp}$. 
DGCONA, 2002a. Tercer Inventario Forestal Nacional, 1997-2006. Galicia, Lugo. Dirección General de Conservación de la Naturaleza, Ministerio de Medio Ambiente, Madrid, $354 \mathrm{pp}$.

DGCONA, 2002b. Tercer Inventario Forestal Nacional, 1997-2006. Galicia, Pontevedra. Dirección General de Conservación de la Naturaleza, Ministerio de Medio Ambiente, Madrid, 314 pp.

Eerikäinen, K., 2003. Predicting the height-diameter pattern of planted Pinus kesiya stands in Zambia and Zimbabwe. Forest Ecology and Management 175, 355366.

Fang, Z., Bailey, R.L., 1998. Height-diameter models for tropical forest on Hainan Island in southern China. Forest Ecology and Management 110, 315-327.

FEARMAGA, 2009. Resultados Industria Forestal de Galicia 2008. Federación Empresarial de Aserradores y Rematantes de Maderas de Galicia. Santiago de Compostela, Spain, $13 \mathrm{pp}$.

García, O., Ruiz, F., 2003. A growth model for eucalypt in Galicia, Spain. Forest Ecology and Management 173, 49-62.

Goldstein, H., 1995. Multilevel Statistical Models, 2nd ed. Halstead Press, New York, $178 \mathrm{pp}$.

Gaffrey, D., 1988. Forstamts-und bestandesindividuelles Sortimentierungsprogramm als Mittel zur Planung, Aushaltung und Simulation. Diploma Thesis. Göttingen, Forstwissenschaftlicher Fachbereich, 86 pp.

Gregoire, T.G., 1987. Generalized error structure for forestry yield models. Forest Science 33, 423-444.

Gregoire, T.G., Schabenberger, O., Barrett, J.P., 1995. Linear modelling of irregularly spaced, unbalanced, longitudinal data from permanent plot measurements. Canadian Journal of Forest Research 25, 137-156.

Hall, D.B., Bailey, R.L., 2001. Modeling and prediction of forest growth variables based on multilevel nonlinear mixed models. Forest Science 47, 311-321.

Hanus, M.L., Marshall, D.D., Hann, D.W., 1999. Height-Diameter Equations for Six Species in the Coastal Regions of the Pacific Northwest. Research Contribution 25. Forest Research Laboratory, Oregon State University, Corvallis, OR, $11 \mathrm{pp}$.

Harrison, W.C., Burk, T.E., Beck, D.E., 1986. Individual tree basal area increment and total height equations for Appalachian mixed hardwoods after thinning. Southern Journal of Applied Forestry 10, 99-104.

Huang, S., Price, D., Titus, S.J., 2000. Development of ecoregion-based heightdiameter models for white spruce in boreal forests. Forest Ecology and Management 129, 125-141.

Huang, S., Yang, Y., Wang, Y., 2003. A critical look at procedures for validating growth and yield models. In: Amaro, A., Reed, D., Soares, P. (Eds.), Modelling Forest Systems. CAB International, Wallingford, Oxfordshire, UK, pp. 271-293.

Huber, P.J., 1973. Robust regression: asymptotics, conjectures, and Monte Carlo. Annals of Statistics 1, 799-821.

ICONA, 1993. Segundo Inventario Forestal Nacional. Ministerio de Agricultura, Pesca y Alimentación, $337 \mathrm{pp}$.

Kish, L., 1992. Weighting for unequal $P_{i}$. Journal of Official Statistics 8 (2), 183-200.

Kozak, A., Kozak, R., 2003. Does cross validation provide additional information in the evaluation of regression models? Canadian Journal of Forest Research 33, 976-987.

Krumland, B.E., Wensel, L.C., 1988. A generalized height-diameter equation for coastal California species. Western Journal of Applied Forestry 3, 113-115.

Lappi, J., 1997. A longitudinal analysis of height/diameter curves. Forest Science 43, 555-570.

Larsen, D.R., Hann, D.W., 1987. Height-Diameter Equations for Seventeen Tree Species in Southwest Oregon. Research Paper 49. Forest Research Laboratory, Oregon State University, Corvallis, OR, 16 pp.

Lindstrom, M.J., Bates, D.M., 1990. Nonlinear mixed effects for repeated measures data. Biometrics 46, 673-687.

Litell, R.C., Milliken, G.A., Stroup, W.W., Wolfinger, R.D., Schabenberger, O., 2006. SAS $^{\mathbb{B}}$ for Mixed Models, 2nd ed. SAS Institute Inc., Cary, NC, $814 \mathrm{pp}$.

Loetsch, F., Zörer, F., Haller, K.E., 1973. Forest Inventory, vol. II. BLV Verlagsgesellschaft, München, $469 \mathrm{pp}$.

Longford, N.T., 1993. Random Coefficient Models. Clarendon Press, Oxford, 270 pp.

López Sánchez, C.A., Gorgoso Varela, J., Castedo Dorado, F., Rojo Alboreca, A., Rodríguez Soalleiro, R., Alvarez González, J.G., Sánchez Rodríguez, F., 2003. A height-diameter model for Pinus radiata D. Don in Galicia (Northwest Spain). Annals of Forest Science 60, 237-245.

Meyer, H.A., 1940. A mathematical expression for height curves. Journal of Forestry 38, 415-420.

Morrison, M.L., Marcot, B.G., Mannan, R.W., 1992. Wildlife Habitat Relationships: Concepts and Applications. Univ. Wisconsin Press, Madison, 343 pp.

Myers, R.H., 1990. Classical and Modern Regression with Applications, 2nd ed. Duxbury Press, Belmont, 488 pp.

Newton, P.F., Amponsah, I.G., 2007. Comparative evaluation of five height-diameter models developed for black spruce and jack pine stand-types in terms of goodness-of-fit, lack-of-fit and predictive ability. Forest Ecology and Management 247, 149-166.

Niklas, K.J., 1995. Size-dependent allometry of tree height, diameter and trunktaper. Annals of Botany 75, 217-227.

Nutto, L., Touza Vázquez, M.C., 2004. High quality eucalyptus sawlog production. In: Borralho, N.M.G., Pereira, J.S., Marques, C., Coutinho, J., Madeira, M., Tomé, M. (Eds.), Eucalyptus in a Changing World. Proc. IUFRO Conf., Aveiro, Portugal, 1115 October 2004, pp. 658-666.

Parresol, B.R., 1992. Baldcypress height-diameter equations and their prediction confidence interval. Canadian Journal of Forest Research 22, 1429-1434.

Peng, C., 1999. Nonlinear Height-Diameter Models for Nine Boreal Forest Tree Species in Ontario. OFRI-Rep. 155. Ontario Forest Research Institute, Ministry of Natural Resources, 28 pp.

Peng, C., Zhang, L., Huang, S., Zhou, X., Parton, J., Woods, M., 2001. Developing Ecoregion-based Height-Diameter Models for Jack Pine and Black Spruce in Ontario. Forest Research Report 159. Ministry of Natural Resources, Ontario Forest Research Institute, Ontario, $10 \mathrm{pp}$.

Pfeffermann, D., Skinner, C.J., Holmes, D.J., Goldstein, H., Rasbash, J., 1998. Weighting for unequal selection probabilities in multilevel models. Journal of the Royal Statistical Society. Series B (Statistical Methodology) 60 (1), 23-40.

Pienaar, L.V., Harrison, W.M., Rheney, J.W., 1990. PMRC Yield Prediction System for Slash Pine Plantations in the Atlantic Coast Flatwoods. PMRC Technical Report 1990-3. School of Forest Resources, University of Georgia, Athens, GA, $31 \mathrm{pp}$.

Pinheiro, J.C., Bates, D.M., 1998. Model Building for Nonlinear Mixed Effects Model. Department of Biostatistics and Department of Statistics, University of Wisconsin, Madison, Wis., 11 pp.

Richards, F.J., 1959. A flexible growth function for empirical use. Journal of Experimental Botany 10, 290-300.

Schnute, J., 1981. A versatile growth model with statistically stable parameters. Canadian Journal of Fisheries and Aquatic Sciences 38, 1128-1140.

Schwarz, G., 1978. Estimating the dimension of a model. The Annals of Statistics 5 (2), 461-464

Sharma, M., Parton, J., 2007. Height-diameter equations for boreal tree species in Ontario using a mixed-effects modeling approach. Forest Ecology and Management 249, 187-198.

Sharma, M., Zhang S.Y. 2004. Height-diameter models using stand characteristics for Pinus banksiana and Picea mariana. Scandinavian Journal of Forest Research 19, 442-451.

Soares, P., Tomé, M., 2002. Height-diameter equation for first rotation eucalypt plantations in Portugal. Forest Ecology and Management 166, 99109.

Spies, T.A., Cohen, W.B., 1992. An Index of Canopy Height Diversity. Coastal Oregon Productivity Enhancement Program Report 5, 5-7. Oregon State University, Corvallis, OR

Temesgen, H., Gadow, K.v., 2004. Generalized height-diameter models-an application for major tree species in complex stands of interior British Columbia. European Journal of Forest Research 123, 45-51.

Tomé, M., 1989. Modelação do crescimento da árvore individual em povoamentos de Eucalyptus globulus Labill. ( $1^{\text {a }}$ rotação) na região centro de Portugal. Ph.D. Thesis. Instituto Superior de Agronomía, Universidade Técnica de Lisboa, Lisbon, Portugal, 256 pp.

Trincado, G., VanderSchaaf, C.L., Burkhart, H.E., 2007. Regional mixed-effects height-diameter models for loblolly pine (Pinus taeda L.) plantations. European Journal of Forest Research 126, 253-262.

Vonesh, E.F., Chinchilli, V.M., 1997. Linear and Nonlinear Models for the Analysis of Repeated Measurements. Marcel Dekker Inc., New York, 560 pp.

West, P.W., Ratkowsky, D.A., Davis, A.W., 1984. Problems of hypothesis testing of regressions with multiple measurements from individual sampling units. Forest Ecology and Management 7, 207-224.

Yang, R.C., Kozak, A., Smith, J.H., 1978. The potential of Weibull-type functions as a flexible growth curve. Canadian Journal of Forest Research 8, 424-431.

Yuancai, L., Parresol, B.R., 2001. Remarks on Height-Diameter Modelling. USDA Forest Service, Research Note SRS-10, Southern Research Station, Asheville, NC 5 pp.

Zeide, B., Vanderschaaf, C., 2002. The effect of density on the height-diameter relationship. In: Outcalt, K.W. (ed). Proceedings of the 11th Biennial Southern Silvicultural Research Conference. 2001 March 20-22, Knoxville, TN. USDA Forest Service, Gen. Tech. Rep. SRS-48, Asheville, NC, pp. 463-466.

Zhang, L., 1997. Cross-validation of nonlinear growth functions for modeling tree height-diameter distributions. Annals of Botany 79, 251-257.

Zhang, S.A., Burkhart, H.E., Amateis, R.L., 1997. The influence of thinning on tree height and diameter relationships in loblolly pine plantations. Southern Journal of Applied Forestry 21, 199-205. 